\title{
Anesthetic Management of a Patient with Gilbert's Syndrome for Spine Surgery: A Case Report
}

\author{
Bhagya R. Jena ${ }^{1} \quad$ Ankur Khandelwal ${ }^{1} \quad$ Mihir P. Pandia ${ }^{1}$ \\ ${ }^{1}$ Department of Neuroanaesthesiology and Critical Care, \\ Neurosciences Centre, All India Institute of Medical Sciences, \\ New Delhi, India
}

\author{
Gyaninder P. Singh ${ }^{1}$
}

\begin{abstract}
Address for correspondence Mihir P. Pandia, MD, Department of Neuroanaesthesiology and Critical Care, Room No. 709, Neurosciences Centre, All India Institute of Medical Sciences, New Delhi 110029, India (e-mail: pandiamihir@gmail.com).
\end{abstract}
Abstract
Keywords
- anesthesia
- Gilbert's syndrome
- hyperbilirubinemia
- spine surgery

Gilbert's syndrome, a hereditary disorder characterized by mild unconjugated hyperbilirubinemia, poses multiple anesthetic challenges during major surgery. Despite an indolent course, it can manifest with severe jaundice in the postoperative period. Anesthetic strategies should be based on thorough preoperative planning, minimizing fasting period, maintaining hepatic blood flow, avoiding hepatotoxic drugs, and reducing surgical duration, blood loss, and blood transfusion. We report the successful management of a case of Gilbert's syndrome for lumbar spine surgery along with a review of literature.

\section{Introduction}

Gilbert's syndrome (GS) is an inherited disorder of hepatic bilirubin metabolism characterized by mild unconjugated hyperbilirubinemia in the absence of hemolysis or underlying liver disease. ${ }^{1,2}$ It is transmitted as an autosomal dominant hereditary disorder with an incidence of 3 to $10 \%$. In India, the incidence of GS is as high as $20 \% \%^{2,3}$ The underlying pathophysiology is due to the deficiency of enzyme bilirubinuridine diphosphate glucuronyl transferase. ${ }^{1-3}$ Majority of GS patients present with mild jaundice (serum bilirubin < $6 \mathrm{mg} / \mathrm{dL}$ ), but exposure to triggering factors, such as stress, infection, prolonged fasting, alcohol use, malnutrition, exercise, and menstruation, can exacerbate the disease process. ${ }^{4}$ Surgery and anesthesia are stressful events, which can cause postoperative serum bilirubin surge. We report the successful anesthetic management of a case of GS for lumbar spine surgery and reviewed the available literature.

\section{Case Report}

A 23-year-old male patient $(90 \mathrm{~kg} / 180 \mathrm{~cm})$ with a past history of GS was posted for surgery of L3-L4 and L4-L5 prolapsed intervertebral disc. Preoperatively, the patient had mild icterus and a serum bilirubin (total) of 2.6 $\mathrm{mg} / \mathrm{dL}$, unconjugated bilirubin $2 \mathrm{mg} / \mathrm{dL}$, and conjugated bilirubin $0.6 \mathrm{mg} / \mathrm{dL}$. Other blood investigations including chest X-ray and electrocardiography were unremarkable. Routine urine examination did not show presence of urobilinogen, bile pigments, or bile salts. Peripheral blood smear showed predominantly normochromic red blood cells with moderate anisocytosis, spherocytosis, and macrocytosis. Ultrasonography abdomen showed grade 1 fatty liver disease. The case was scheduled as the first case on the day of surgery. Preoperatively, the patient received ranitidine $150 \mathrm{mg}$, the night before surgery and again on the morning of surgery. The patient was allowed to have clear fluids till 2 hours before surgery. Intravenous (IV) $5 \%$ dextrose was commenced on the morning of surgery (100 mL/hour). Intramuscular glycopyrrolate $(0.2 \mathrm{mg}$ ) was administered 30 minutes prior to shifting the patient to operating room (OR). In the OR, standard baseline vitals were recorded (heart rate: 83 beats/minute [bpm], noninvasive blood pressure 129/77 [94] mm Hg, blood oxygen saturation $99 \%$ on room air, temperature $36.1^{\circ} \mathrm{C}$ ). General anesthesia was induced with IV fentanyl $150 \mu \mathrm{g}$ and propofol $140 \mathrm{mg}$, and cisatracurium $10 \mathrm{mg}$ IV was used to facilitate tracheal intubation. Anesthesia was maintained with $\mathrm{O}_{2}: \mathrm{N}_{2} \mathrm{O}(2: 3)$, isoflurane (0.8-1.0 MAC), and intermittent doses of fentanyl (50 $\mu$ g every hourly) and cisatracurium (2 mg every 30 minutes). Intraoperatively, mean arterial pressure (MAP) was maintained within 10\% of baseline along with strict normothermia and normocapnia. L4 laminectomy and bilateral L3-L4 and L4-L5
DOI https://doi.org/ $10.1055 / \mathrm{s}-0039-1679134$ ISSN 2348-0548.
License terms

()(1) $\Theta \circledast$ 
foraminotomy was performed. Intravenous ondansetron $8 \mathrm{mg}$ was administered 30 minutes before the completion of surgery. The surgical site was also infiltrated with $15 \mathrm{~mL}$ of $0.25 \%$ ropivacaine. At the end of surgery, neuromuscular blockade was reversed with IV neostigmine $(4 \mathrm{mg})$ and glycopyrrolate $(0.8 \mathrm{mg})$. Trachea was extubated after the patient was awake and following verbal commands. No blood or blood products were transfused. In the postoperative period, analgesia was maintained with intramuscular ketorolac $30 \mathrm{mg}$ twice daily and IV fentanyl $25 \mu \mathrm{g}$ as and when required. Maintenance fluid (5\% dextrose and normal saline) was administered at $75 \mathrm{~mL} /$ hour. Few sips of water were allowed orally after 4 hours. Enteral feed was started next day. On the first postoperative day, serum bilirubin (total) was $2.7 \mathrm{mg} / \mathrm{dL}$, unconjugated bilirubin $2 \mathrm{mg} / \mathrm{dL}$, and conjugated bilirubin $0.7 \mathrm{mg} / \mathrm{dL}$. Clinically, the patient did not show any flare-up of jaundice. The patient was discharged home on the fourth postoperative day. Follow-up after 1 month showed serum bilirubin (total) $2.4 \mathrm{mg} / \mathrm{dL}$, unconjugated bilirubin $1.9 \mathrm{mg} / \mathrm{dL}$, and conjugated bilirubin $0.5 \mathrm{mg} / \mathrm{dL}$.

\section{Discussion}

Gilbert's syndrome the most common inherited cause of unconjugated hyperbilirubinemia was first described by Gilbert and Pierre. ${ }^{5}$ Clinical presentation is usually benign and includes mild jaundice and nonspecific symptoms, such as abdominal cramps, fatigue, and malaise. Despite an indolent course, the disease can aggravate under the influence of various stressors. Surgery and anesthesia are one such stressor. Regional anesthesia appropriately blunts neuroendocrine response and should be ideally practiced in patients with GS; however, the size and site of the pathology, the position of the patient, and duration of surgery preclude its universal use. To our knowledge, anesthetic management of GS during spine surgery has not been described before.

Various preoperative factors affect postoperative outcome in GS. Thorough preoperative assessment is the most important component of treatment of patients with GS. To minimize the duration of fasting, surgery should be scheduled as the first case in the morning. Hyperbilirubinemia following caloric restriction is attributed to either increased bilirubin production secondary to enhanced microsomal heme-oxygenase activity ${ }^{6}$ or decrease in bilirubin clearance. ${ }^{7}$ Postoperative jaundice due to the stress of reduced caloric intake has been previously reported. ${ }^{8}$ Glucose infusion should be started before surgery so as to avoid hypoglycemia and caloric deficiency.

In the intraoperative period, various anesthetic considerations include maintenance of MAP within $10 \%$ of baseline or at least MAP $>65 \mathrm{~mm} \mathrm{Hg}$ to ensure optimal hepatic perfusion, avoiding hepatotoxic drugs and hypoglycemia, ensuring adequate analgesia to blunt neuroendocrine response, target-controlled administration of drugs to avoid overdosing and prevention of hypothermia. Various surgical factors, such as reducing the duration of surgery, blood loss, tissue retraction, and excellent hemostasis, should also be taken into consideration. Reabsorption of big hematoma and blood
Table 1 Perioperative targets in Gilbert's syndrome

\begin{tabular}{|l|l|}
\hline Anesthetic factors & Surgical factors \\
\hline $\begin{array}{l}\text { 1. Minimize the preoperative } \\
\text { fasting period so as to avoid } \\
\text { hypoglycemia }\end{array}$ & $\begin{array}{l}\text { 1. Minimize the duration } \\
\text { of surgery } \\
\text { 2. Minimize blood loss }\end{array}$ \\
$\begin{array}{l}\text { 2. Maintain mean arterial pres- } \\
\text { sure within 10\% of baseline }\end{array}$ & $\begin{array}{l}\text { 3. Less tissue retraction } \\
\text { 4. Excellent hemostasis }\end{array}$ \\
$\begin{array}{l}\text { 3. Avoid hepatotoxic drugs } \\
\text { 5. Adevent hypothermia }\end{array}$ & \\
\hline
\end{tabular}

transfusion are the other factors that can precipitate postoperative jaundice. ${ }^{9}$ Various anesthetic and surgical factors affecting outcome have been summarized in - Table 1 .

In the $\mathrm{OR}$, anesthetic drugs that are metabolized or biotransformed by glucuronyl transferase in the liver should ideally be avoided to prevent worsening of symptoms. Propofol is the preferred induction agent as it increases total hepatic blood flow (HBF) in both hepatic arterial and portal venous circulation, suggesting a significant vasodilator effect. ${ }^{10}$ On the other hand, thiopental may decrease HBF due to increased hepatic arterial vascular resistance. ${ }^{11}$ Moreover, thiopentone and ketamine affect hepatic functions in a dose-dependent fashion. Like atracurium, cisatracurium is metabolized by Hofmann elimination and is the preferred neuromuscular blocking agent. It is approximately four times as potent as atracurium and produces five times less laudanosine in contrast to atracurium. Moreover, it does not cause histamine release. Among newer inhalational agents, isoflurane has been the most commonly used volatile anesthetic agent in GS due to minimal interference with HBF. Despite minimal liver metabolism $(0.02 \%)$ and low solubility, desflurane has been shown to decrease HBF in a dose-dependent fashion. Among opioids, remifentanil has no or minimal effect on liver functions as it is an ester degraded by plasma and tissue esterases, thus making it an ideal agent for patients with GS. However, in its nonavailability, fentanyl can be used as its metabolism is not significantly altered in patients with liver disease. Among the nonopioid analgesics, paracetamol is avoided as it is metabolized by enzyme also deficient in some cases of GS. ${ }^{12}$ Thus, risks of worsening of liver functions exist with the use of paracetamol in GS. Dexmedetomidine, an $\alpha 2$ receptor agonist, has been shown to reduce reperfusion injury during liver transplantation in addition to reduction in anesthetic requirements. ${ }^{13,14}$ Animal studies have also shown that dexmedetomidine protects lung alveolar epithelial cell from bilirubin-induced injury. ${ }^{15}$ However, its effect on HBF is yet to be thoroughly studied. Nevertheless, the sympatholytic property of dexmedetomidine and consequent hypotension should be kept in mind.

The intraoperative monitoring of hepatic perfusion is ideal to guide the effectiveness of anesthetic goals. There are various techniques to monitor HBF intraoperatively, which are invasive and not feasible. ${ }^{16} \mathrm{HBF}$ using transesophageal echocardiography has been estimated successfully both in cardiac and noncardiac surgeries. ${ }^{16,17}$ However, lack of availability in all centers, high-cost, semi-invasiveness, and requirement of expert hands still make it an unpopular technique to estimate 
HBF. Measurement of the liver tissue oxygenation noninvasively using near-infrared spectroscopy (NIRS) is possible by applying NIRS probe transcutaneously over the palpable liver and directly below the right costal arch. ${ }^{18}$ However, the technique has not been studied on a large scale.

\section{Conclusion}

Gilbert's syndrome is not a rare condition and thus understanding the pathophysiology of this disease is of utmost importance for anesthesiologists. Despite a benign course, it can manifest with severe jaundice in the postoperative period. Wherever applicable, regional anesthesia should be the preferred technique. However, with the advent of new drugs, margin of safety with general anesthetics has increased tremendously. Anesthetic strategies should be based on thorough preoperative planning, minimizing fasting period, maintaining HBF, avoiding hepatotoxic drugs, and reducing surgical duration, blood loss, and blood transfusion.

\section{Conflict of Interest}

None declared.

\section{References}

1 Wolkoff AW. The hyperbilirubinemias. In: Fauci AS, Braunwald E, Kasper DL, Hauser SL, Longo DL, Jameson JL, Loscalzo J, eds. Harrison's Principles of Internal Medicine. 17th edition. New York: McGraw-Hill; 2008:1929

2 Nishi H, Sakaguchi T, Miyagawa S, Yoshikawa Y, Sawa Y. Cardiac surgery in patients with Gilbert's syndrome. J Card Surg 2012;27(1):60-61

3 Wagner KH, Shiels RG, Lang CA, Seyed Khoei N, Bulmer AC. Diagnostic criteria and contributors to Gilbert's syndrome. Crit Rev Clin Lab Sci 2018;55(2):129-139

4 Rasool A, Sabir S, Ashlaq M, Farooq U, Khan MZ, Khan FY. Gilbert's syndrome - a concealed adversity for physicians and surgeons. J Ayub Med Coll Abbottabad 2015;27(3):707-710

5 Gilbert A, Lereboullet P. La cholemie simple familiale. Sem Med 1901;21:241-243

6 Bakken AF, Thaler MM, Schmid R. Metabolic regulation of heme catabolism and bilirubin production. I. Hormonal control of hepatic heme oxygenase activity. J Clin Invest 1972;51(3):530-536
7 Bloomer JR, Barrett PV, Rodkey FL, Berlin NI. Studies on the mechanism of fasting hyperbilirubinemia. Gastroenterology 1971;61(4):479-487

8 Quinn NW, Gollan JL. Jaundice following oral surgery: Gilberts syndrome. Br J Oral Surg 1975;12(3):285-288

9 Taylor S. Gilbert's syndrome as a cause of postoperative jaundice. Anaesthesia 1984;39(12):1222-1224

10 Carmichael FJ, Crawford MW, Khayyam N, Saldivia V. Effect of propofol infusion on splanchnic hemodynamics and liver oxygen consumption in the rat. A dose-response study. Anesthesiology 1993;79(5):1051-1060

11 Thomson IA, Fitch W, Hughes RL, Campbell D, Watson R. Effects of certain i.v. anaesthetics on liver blood flow and hepatic oxygen consumption in the greyhound. $\mathrm{Br} \mathrm{J}$ Anaesth 1986;58(1):69-80

12 Rauchschwalbe SK, Zühlsdorf MT, Wensing G, Kuhlmann J. Glucuronidation of acetaminophen is independent of UGT1A1 promotor genotype. Int $\mathrm{J}$ Clin Pharmacol Ther 2004;42(2):73-77

13 Fayed NA, Sayed EI, Saleh SM, Ehsan NA, Elfert AY. Effect of dexmedetomidine on hepatic ischemia-reperfusion injury in the setting of adult living donor liver transplantation. Clin Transplant 2016;30(4):470-482

14 Sayed E, Yassen KA. Intraoperative effect of dexmedetomidine infusion during living donor liver transplantation: a randomized control trial. Saudi J Anaesth 2016;10(3):288-294

15 Cui J, Zhao H, Yi B, Zeng J, Lu K, Ma D. Dexmedetomidine attenuates bilirubin-induced lung alveolar epithelial cell death in vitro and in vivo. Crit Care Med 2015;43(9):e356-e368

16 Meierhenrich R, Gauss A, Mühling B, et al. The effect of propofol and desflurane anaesthesia on human hepatic blood flow: a pilot study. Anaesthesia 2010;65(11):1085-1093

17 Nagaraja PS, Singh NG, Subash S, Manjunatha N, Prabhushankar CG, Sathish N. Anesthetic management of a case of Gilbert's syndrome for mitral and aortic valve replacement: role of transesophageal echocardiography. Saudi J Anaesth 2017;11(1):89-92

18 Schulz G, Weiss M, Bauersfeld U, et al. Liver tissue oxygenation as measured by near-infrared spectroscopy in the critically ill child in correlation with central venous oxygen saturation. Intensive Care Med 2002;28(2):184-189 